\title{
Depigmenting Efficacy of Commercially Available Skin-Lightening Creams: Comparative Analysis and In Vivo Evaluation
}

\author{
Rehan Mustafa ${ }^{1}$, Saeed- Ur-Rashid Nazir ${ }^{1, *}$, Naveed Akhtar ${ }^{2}$, Misbha Sultana ${ }^{4}$, Attique-Ur-Rehman \\ Mufti $^{1}$, Naveed Ahmad ${ }^{3}$, M. Nadeem ${ }^{1}$, M. Ameer ${ }^{1}$ and Ghulam Mustafa ${ }^{1}$ \\ ${ }^{I}$ Faculty of Pharmacy, University of Sargodha, 40100, Sargodha, Pakistan \\ ${ }^{2}$ Department of Pharmacy, Islamia University of Bahawalpur, Bahawalpur, Pakistan \\ ${ }^{3}$ Faculty of Pharmacy, Universiti Kebangsaan Malaysia, 50300, Kuala Lumpur, Malaysia \\ ${ }^{4}$ University College of Pharmacy, University of Punjab, Lahore, Pakistan
}

\begin{abstract}
To prevail over the irrational use of commercial skin lightening creams, this study assessed the de-pigmenting efficacy of various branded skin-lightening creams. Four well known branded creams were selected for this purpose and coded as P-I, P-II, P-III and P-IV, respectively. Earlier than In-vivo evaluation of the creams, physicochemical characterization and $I n$-vitro stability studies of the creams were carried out to guarantee the quality of the creams. In-vivo evaluation of the creams was performed in human volunteers. The effects of creams on Erythema, skin melanin, transepidermal water loss (TEWL) and moisture sebum were recorded. Towards the end of the study," Panel test" was conducted with volunteers to review their sensory evaluation about the creams. The results of physicochemical characterization and stability analysis recommended that creams were appropriate for skin application at room temperature. P-I and P-IV creams demonstrated highest de-pigmenting efficacy and controlled the Erythema and TEWL. On the other hand, the skin sebum contents were ideally controlled by P-IV cream while skin moisture contents were increased upto $21.0 \%$ by P-1cream. These results concluded that cream P-I was most suitable for skin-lightening with added advantages of increasing skin hydration and controlling skin sebum contents.
\end{abstract}

Keywords: Cream, De-pigmenting, Erythema and Melanin, Stability.

\section{INTRODUCTION}

In today's global world, people are aware oftheir beauty and well-being. The market share of beauty products used for skin moisturizing, skin whitening, wrinkle care and antiageing is increasing radically. So, numerous skin-lightening products are commercially available over the counter (OTC) to obtain lighter skin complexion. Clinically, such creams are prescribed to treat hyper pigmentation disorders including Melasma and Linea nigra [1]. Even in the cosmetics market, many functional products such as those developed for skin moisturizing, skin whitening, wrinkle care and anti-ageing skin have been launched over last two decades [2]. The misleading advertisement and irrational use of such creams may result in severe adverse consequences to human skin. Thus, it is the need of time to generate awareness among masses about the causes of skin darkness and use of skin lightening creams. Furthermore, the quality, stability and efficacy of commercially available skin lightening agents should be evaluated.

To assess a de-pigmenting agent, it is important to be aware of the mechanism and causes of skin pigmentation.

*Address correspondence to this author at the Faculty of Pharmacy, University of Sargodha, University Road, 41000, Sargodha, Pakistan; Tel: +92-48-9230807; Fax: +92-48-9230799; E-mail: srnazir@yahoo.com
Human skin color is primarily dependent on a pigment called melanin, which is mainly synthesized in organelles of the neurocrest-derived melanocyte in skin [3]. The foremost role of melanin is to shield human skin from harmful effects of UV radiations from sun light [4]. Hyper pigmentation of skin is generally related to an increased number of melanocytes and hyperactivity of tyrosinase enzymes involved in melanogenesis [5]. The biosynthesis of the melanin (melaninogenesis) is improved by over activation of enzyme tyrosinase upon exposure to UV radiations. Tyrosinase isinvolved in the first two steps of melaninogenesis (i) the hydroxylation of L-tyrosine to L-dihydroxyphenylalanine (ii) its subsequent oxidation to the corresponding quinine [6,7]. These steps are the rate-limiting steps in melaninogenesis as rest of synthesis can proceed spontaneously [4].

Even though melanin plays a vital role in protecting skin from UV radiation, yet the over production and accumulation of melanin in specific parts of the skin has become an esthetic problem. This phenomenon has resulted in the discovery of several potent depigmenting agents. As tyrosinase plays a key role in the melaninogenesis, most of the skin lightening agents reduce melanin production by inhibiting enzyme activity [8] through different mechanisms: (i) interference with its transcription and/or glycosylation, (ii) reduction in by-products (iii) inhibition by different modalities and (iv) post-transcriptional control $[9,10]$. 
Table 1. Active Ingredients of the Creams (* as Provided on Product Package) and their Effect on Skin

\begin{tabular}{|c|c|c|}
\hline Code & Active Ingredients* & Effect on Skin \\
\hline \multirow{9}{*}{ P-I } & EthylhexylMethoxycinnamate & Sunscreens (absorb UV-A\&B radiations) \\
\hline & Aluminium Starch Octenylsuccinate & Enhance the sun protection factor \\
\hline & Phenylbenzimidazole Sulfonic Acid & Primarily UV-B protecting agent \\
\hline & Benzyl Salicylate & Absorb UV \\
\hline & CL 77891/titanium dioxide & Opacifying, UV Absorber, UV Filter \\
\hline & Gentianalautea Extract & Antibacterial/Anti-Acne, Anti-Irritant \\
\hline & Sodium citrate & Antioxidant \\
\hline & $\begin{array}{l}\text { Terephthalylidene Dicamphor } \\
\text { Sulphonic acid }\end{array}$ & UV filter \\
\hline & Tetra-sodium EDTA & Chelating agent \\
\hline \multirow{4}{*}{ P-II } & UV Protecting Agents & Sun screening effect \\
\hline & \multirow{2}{*}{ Vitamin B3 } & Anti- aging, Sun screening, Improve skin's \\
\hline & & elasticity, Enhance skin's barrier functions \\
\hline & Vitamin E & Antioxidant, Skin conditioning \\
\hline \multirow{8}{*}{ P-III } & Vitamin B3 & Anti- aging, Sun screening, Improve skin's \\
\hline & \multirow{2}{*}{ Sodium Ascorbyl Phosphate } & elasticity, Enhance skin's barrier functions \\
\hline & & Collagen stimulator, Skin lightener, Antioxidant \\
\hline & Vitamin E & Antioxidant, Skin conditioning \\
\hline & Pyridoxine Hydrochloride & antibacterial and antioxidant \\
\hline & OctylMethoxy Cinnamate & Absorb UV-B and UV-A rays \\
\hline & Butyl Methoxydibenzoylmethane & UV absorber, UV filter \\
\hline & Allantoin & Natural regenerating, Protecting agent \\
\hline \multirow{4}{*}{ P-IV } & Disodium EDTA & Chelating agent \\
\hline & Herbal Extract & As whitening agent \\
\hline & Hydroquinones & Depigmenting agent \\
\hline & Sun Screen Agents & UV protector \\
\hline
\end{tabular}

In addition to the efficacy of the depigmenting agent, the stable and safe formulation of skin lightening creams also plays pivotal role in achieving desired effects. Therefore, the skin lightening creams and agents should be independent of safety and stability issues prior to commercialization. These issues of quality and safety of creams become worse in developing countries. In such countries lack of education, poverty, improper storage facilities and insufficiency of regulatory agencies may lead to the introduction and sale of substandard creams in the market. The irrational use of such creams due to misleading advertisements may result in severe side effects to the human skin. These creams must be screened by proper in vitro and in vivo testing prior to the commercialization.

A number of skin-lightening creams are available OTC in Pakistan. Cream manufacturers attract the consumers by advertising the skin lightening effect of their products in social and main stream media. In this study, we conducted the comparative quality and stability analysis of four commercially available skin lightening creams. There after, effects of creams on skin melanin, erythema, moisture, sebum and trans-epidermal water loss (TEWL) were evaluated in human volunteers.

\section{METHODOLOGY}

\subsection{Materials}

Four Branded skin-lightening creams were purchased from local market in Pakistan. The creams were coded as PI, P-II, P-III and P-IV. The brand names of creams are not mentioned in this manuscript due to legal restrictions. However, the detail of the ingredients claimed by manufacturers on product package and their effects on skin is provided in Table 1.

\subsubsection{Instruments}

The instruments used in this study includes Cutometer, Mexameter, Corneometer, Sebumeter and Tewameter MPA 5, MPA 580 (Courage and Khazaka, Deuschland); To 
measure the humidity, Digital Humidity Meter (TES Electronic Corporation, Taiwan) was used; Cold Incubator (Sanyo MIR-153, Japan); while hot Incubator (Sanyo MIR162, Japan) were used for incubation purpose; ConductivityMeter (WTW COND-197i, Germany); homogenizer (EuroStar, IKA D 230, Germany) and pH-Meter (WTW pH-197i, Germany) were used.

\subsection{Physicochemical Characterization of Creams}

Prior to the application of creams in human volunteers, physicochemical characterization of creams was done to ensure the quality of the creams. The types of creams were assessed by dilution with oil and water separately. The $\mathrm{pH}$ and electrical conductivity values of creams were determined at $8^{\circ} \mathrm{C}+0.1^{\circ} \mathrm{C}, 25^{\circ} \mathrm{C}+0.1^{\circ} \mathrm{C}, 40^{\circ} \mathrm{C} \pm 0.1^{\circ} \mathrm{C}$ and $40^{\circ} \mathrm{C} \pm 0.1^{\circ} \mathrm{C}$ in incubator at $75 \%$ relative humidity $(\mathrm{RH})$.

\subsection{Stability Studies}

Stability tests of products were acquired under various conditions in order to record these effects. The stability parameters were studied carefully by keeping the samples at $8^{\circ} \mathrm{C} \pm 0.1^{\circ} \mathrm{C}$ under refrigeration, $25^{\circ} \mathrm{C} \pm 0.1^{\circ} \mathrm{C}$ (in incubation), $40^{\circ} \mathrm{C} \pm 0.1^{\circ} \mathrm{C}$ (in incubation) and $40^{\circ} \mathrm{C} \pm 0.1^{\circ} \mathrm{C}$ (in incubation) at $75 \%$ relative humidity $(\mathrm{RH})$. All the creams were observed for color change, phase separation and liquefaction at various intervals for 60 days.

\subsection{In vivo Evaluation of Creams}

In vivo evaluation of creams on human skin was performed in eighteen healthy male volunteers (ages: 20$40 y$ ). Before the test, a skin specialist carefully examined theskin conditions of the volunteers. Prior to the study, volunteers were educated about the importance, risks and protocols of the study. The consents of the volunteers were obtained prior to study. On first day, burchard test was performed in order to check any side reaction of the creams. Mexameter was used to mark a specified area on forearms and values for melanin and erythema were recorded. Each sample (1.0 g approx.) was applied to the marked regions and was covered with the surgical dressing thereafter. After $24 \mathrm{~h}$, the values for melanin and erythema were noted on both forearms. On second day of the study, each participant was provided with two creams for application on the cheeks. Both of the creams were specified for "right" and "left" cheek. The volunteers were instructed to apply the cream twice a day for 8 weeks. Skin measurements were taken for each individual at end of the week 1-6 and 8 .

\subsubsection{Skin Melanin and Erythema}

The skin melanin contents and erythema were measured prior to the application of any cream by using mexameter and then after application of creams at the end of the week 16 and 8.

\subsubsection{Skin Moisture Contents}

Skin moisture contents were measured on both cheeks on day one and at the end of week 1-6 and 8 of the study with the help of Corneometer.

\subsubsection{Skin Sebum Contents}

Sebumeter was used to measure the skin sebum contents before application of creams and at the end of week 1-6 and 8 of study.

\subsubsection{Trans Epidermal Water Loss (TEWL)}

Net TEWL from the skin was measured by the help of a Tewameter before application of creams and at the end of week 1-6 and 8 of study.

\subsubsection{Panel Test}

At the end of $8^{\text {th }}$ week of study, panel test was conducted with the volunteers to obtain their observations about the creams. Different parameters of sensory evaluation like ease of application, shine on skin and sense of softness, sense just after application, irritation, spread ability, sense in long term, were recorded from each individual.

\subsection{Statistical Analysis}

The statistical analysis of different measured parameters was conducted (sebum, skin moisture, erythema, melanin, TEWL, elasticity, $\mathrm{pH}$ and electrical conductivity by using software (SPSS 17.0). Two-way ANOVA was applied to assess the statistical significance of the results.

\section{RESULTS}

\subsection{Physicochemical Characterization of Creams}

The results of the physiochemical characterization of the creams are presented in Table 2. The $\mathrm{pH}$ and electrical conductivity of creams were determined at $8^{\circ} \mathrm{C} \pm 0.1^{\circ} \mathrm{C}$, $25^{\circ} \mathrm{C} \pm 0.1^{\circ} \mathrm{C}, 40^{\circ} \mathrm{C} \pm 0.1^{\circ} \mathrm{C}$ and $40^{\circ} \mathrm{C} \pm 0.1^{\circ} \mathrm{C}$ in incubator at $75 \%(\mathrm{RH})$ to evaluate the effect of these conditions on the creams. The $\mathrm{pH}$ value of the all the creams at tested conditions ranged from 5 to 7 suggesting that these creams were suitable for application on skin [11]. The electrical conductivity of the creams was lowest for P-IV cream ranging from 124 to 141 whereas the electrical conductivity of the cream P-I, P-II and P-III ranged from 309 to 352. However, the electrical conductivity for P-2 at $40^{\circ} \mathrm{C}$ was above 400 .

\subsection{Stability Studies}

The results of the stability studies of the creams are shown in Table 3. All the creams were tested at $8^{\circ} \mathrm{C} \pm 0.1^{\circ} \mathrm{C}$, $25^{\circ} \mathrm{C} \pm 0.1^{\circ} \mathrm{C}, 40^{\circ} \mathrm{C} \pm 0.1^{\circ} \mathrm{C}$ and $40^{\circ} \mathrm{C} \pm 0.1^{\circ} \mathrm{C}$ at $75 \%$ relative humidity $(\mathrm{RH})$ to observe any change in color, phase separation and liquefaction. No change in color of the creams was observed at all the tested conditions as can be seen in Table 3. Similarly, no liquefaction and phase separation was observed for creams P-I and P-II. However, prominent liquefaction and phase separation was seen in $\mathrm{P}-\mathrm{I}$ and $\mathrm{P}-\mathrm{II}$ at $40^{\circ} \mathrm{C} \pm 0.1^{\circ} \mathrm{C}$ and $40^{\circ} \mathrm{C} \pm 0.1^{\circ} \mathrm{C}$ at $75 \%$. These findings indicated that these creams are not suitable for usage at $40^{\circ} \mathrm{C}$.

\subsection{In vivo Evaluation of Creams}

Prior to in vivo study, Burchard test was performed on the forearms of each volunteer to determine any possible reaction to the creams. The results of the Burchard test showed no reaction (irritation, hypersensitivity) to creams indicating that the volunteers were fit for study.

\subsubsection{Skin Melanin and Erythema}

The weekly percent change in the skin melanin contents as determined by Mexameter are shown in Fig. (1a). It was 
Table 2. Physical Characteristics of the Creams P-I, P-II P-III and P-IV where W Represents White, OW Represents off-White, N Represent no Change, $P$ Represents Prominent Change and "stands for $75 \%$ RH

\begin{tabular}{|c|c|c|c|c|c|c|c|c|c|c|c|c|c|c|c|c|c|c|c|c|c|}
\hline \multicolumn{2}{|c|}{ Time } & \multicolumn{4}{|c|}{ Fresh } & \multicolumn{4}{|c|}{15 Days } & \multicolumn{4}{|c|}{30 Days } & \multicolumn{4}{|c|}{45 Days } & \multicolumn{4}{|c|}{60 Days } \\
\hline & & $8^{\circ} \mathrm{C}$ & $25^{\circ} \mathrm{C}$ & $40^{\circ} \mathrm{C}$ & ${ }^{*} 40^{\circ} \mathrm{C}$ & $8^{\circ} \mathrm{C}$ & $25^{\circ} \mathrm{C}$ & $40^{\circ} \mathrm{C}$ & ${ }^{*} 40^{\circ} \mathrm{C}$ & $8^{\circ} \mathrm{C}$ & $25^{\circ} \mathrm{C}$ & $40^{\circ} \mathrm{C}$ & ${ }^{*} 40^{\circ} \mathrm{C}$ & $8^{\circ} \mathrm{C}$ & $25^{\circ} \mathrm{C}$ & $40^{\circ} \mathrm{C}$ & ${ }^{*} 40^{\circ} \mathrm{C}$ & $8^{\circ} \mathrm{C}$ & $25^{\circ} \mathrm{C}$ & $40^{\circ} \mathrm{C}$ & ${ }^{*} 40^{\circ} \mathrm{C}$ \\
\hline \multirow{3}{*}{$\frac{\pi}{2}$} & PI & 6.5 & 6.5 & 6.5 & 6.5 & 6.7 & 6.8 & 6.3 & 6.2 & 6.6 & 6.5 & 6.2 & 5.8 & 6.5 & 6.7 & 6.1 & 6.1 & 6.5 & 6.8 & 6.1 & 6.5 \\
\hline & PII & 6.1 & 6.1 & 6.1 & 6.0 & 6.3 & 6.4 & 5.3 & 5.3 & 6.1 & 6.0 & 5.1 & 5.0 & 6.3 & 5.9 & 4.9 & 4.8 & 6.4 & 6.0 & 4.8 & 4.7 \\
\hline & PIV & 6.1 & 6.1 & 6.1 & 6.1 & 6.2 & 6.3 & 6.1 & 6.2 & 6.2 & 6.0 & 5.9 & 5.4 & 6.2 & 5.8 & 5.7 & 5.5 & 6.4 & 6.0 & 5.5 & 5.8 \\
\hline \multirow{3}{*}{ 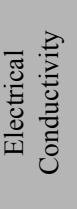 } & PI & 315 & 315 & 315 & 315 & 315 & 339 & 337 & 313 & 318 & 335 & 323 & 341 & 326 & 337 & 312 & 347 & 322 & 327 & 351 & 349 \\
\hline & PII & 330 & 330 & 330 & 330 & 301 & 339 & 370 & 348 & 311 & 347 & 389 & 341 & 300 & 351 & 470 & 379 & 322 & 327 & 489 & 401 \\
\hline & PIII & 309 & 309 & 309 & 309 & 313 & 339 & 331 & 313 & 316 & 338 & 323 & 347 & 324 & 335 & 312 & 346 & 322 & 327 & 351 & 349 \\
\hline
\end{tabular}

Table 3. The pH and Electrical Conductivity Values of P-I, P-II, P-III and P-IV Creams at Different Storage Conditions where * Stands for $75 \%$ RH

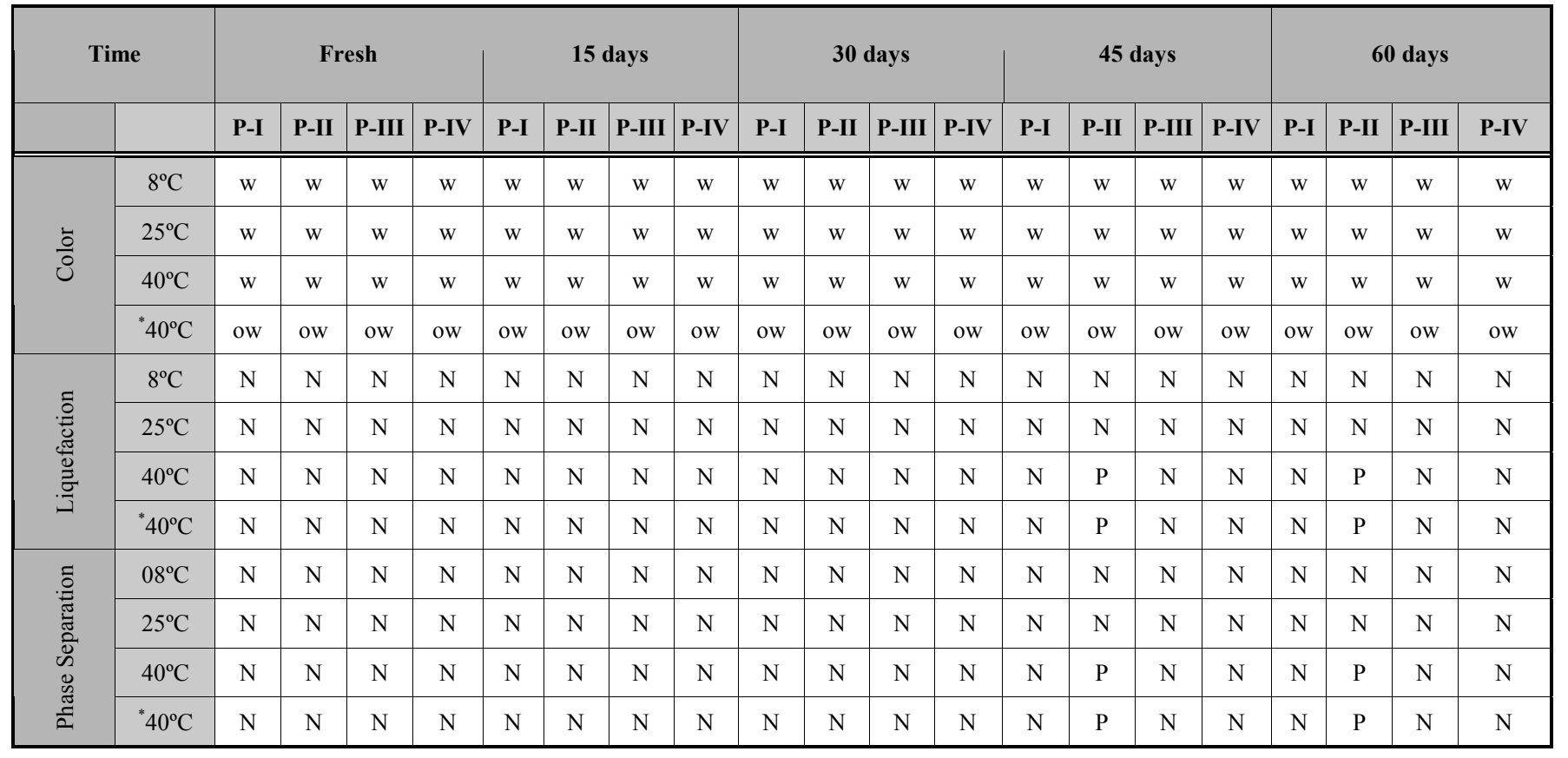

found that cream P-I and P-II were more efficient in decreasing the skin melanin level than cream P-II and P-II. The cream P-I contains broad spectrum sunscreen agents (Table 1). As production of melanin is induced by UVradiation, it can be suggested that skin lightening effect of $\mathrm{P}$ I might be due to UV protect ants used in its formulation [12, 13]. On the other hand, depigmenting effect of P-IV can be attributed to the presence of hydroquinone which is one of the strongest inhibitor, which plays key role in melaninogenesis [14-16]. The skin attributed to presence of UV protectants and vitamin B3, C and $\mathrm{E}$ in the formulation [13]. Previous reports also suggest that these vitamins can play an important role in skin whitening $[17,18]$.

The trends of percent change in skin erythema are presented in Fig. (1b) and the net change in erythema at the end of study is shown in Fig. (2). As evident from the figure cream P-I showed maximum decrease in skin erythema (13.26\%). Whereas creams P-I, P-II and P-III showed $8.84 \%, 8.9 \%$ and $9.5 \%$ decrease respectively which was lesser than P-I.

\subsubsection{Trans Epidermal Water Loss (TEWL)}

Fig. (1c) represents the weekly decrease in TEWL from volunteer's skin as measured by Tewameter and Fig. (2) represents the net TEWL at the end of study. The results revealed that cream P-I and P-II showed highest decrease in TEWL from the volunteer's skin. The order of decreasing TEWL among the creams was found to be P-I $>$ P-II $>$ P-III $>$ P-IV with $23.48 \%, 22.33 \%, 17.95 \%$ and $14.83 \%$ net decrease in TEWL, respectively. This greater decrease in 

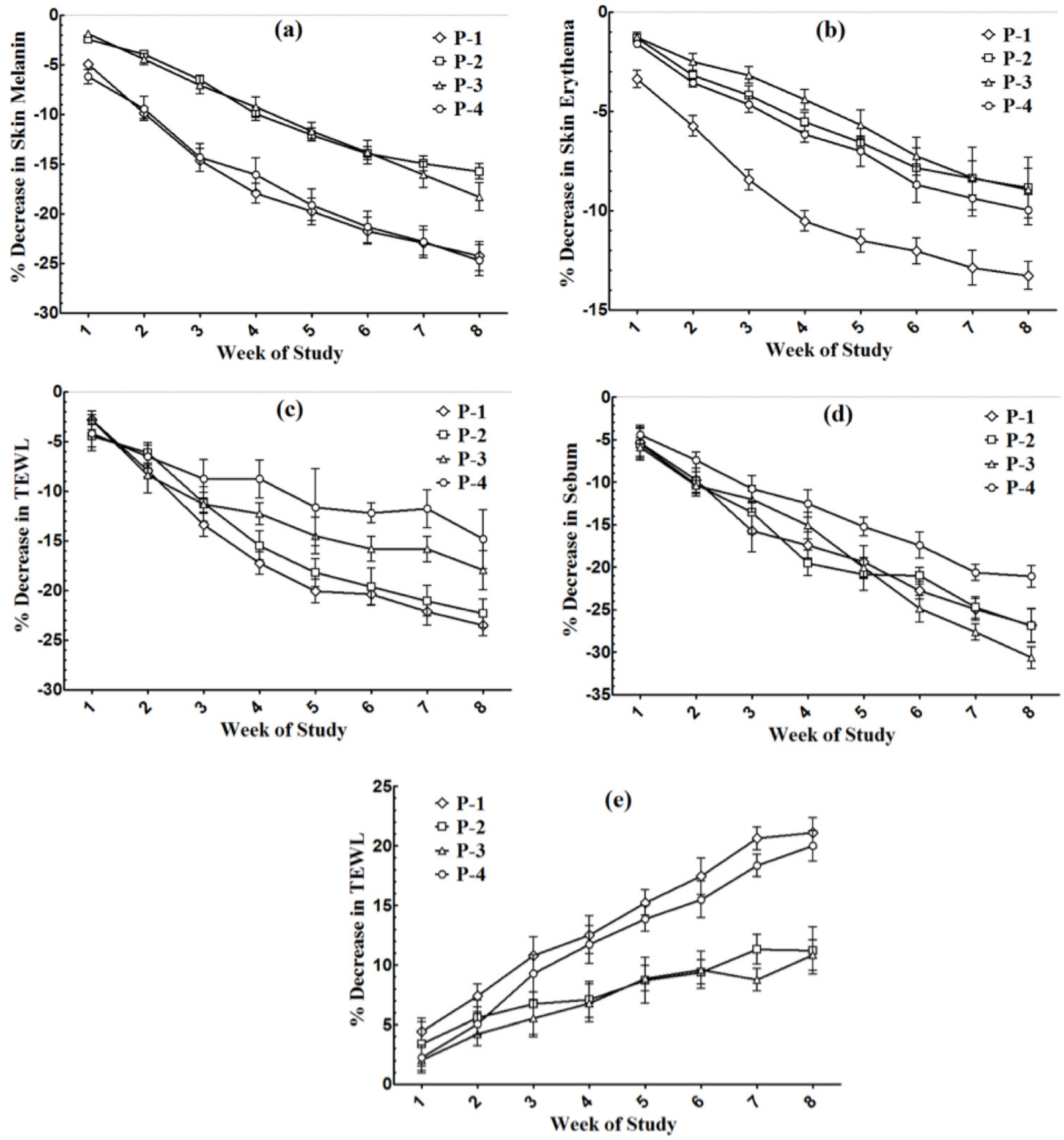

Fig. (1). The percent weekly change in skin melanin (a), erythema (b) TEWL (c), sebum (d), and moisture (e). Mean \pm SEM (n=9).

TEWL by P-1 and P-2 could be due to presence of humectants in the formulation of the creams.

\subsubsection{Skin Sebum Contents}

Sebumeter was used to measure the skin sebum contents and the results are presented in Fig. (1d) and Fig. (2). It was found that all the creams were good at decreasing skin sebum contents. However, P-IV and P-II were most efficient for this purpose with 30.2 and $27.5 \%$ decrease in sebum respectively. These results suggest that these two creams could be more suitable for persons with oily skin, and could be beneficial to control acne.

\subsubsection{Skin Moisture Contents}

Skin moisture contents of volunteers were measured with corneometer to evaluate the increase in skin hydration after the use of cream. The increasing weekly trend in skin moisture contents of the volunteers is presented in Fig. (1e). Among the creams P-I and P-IV were most efficient in hydrating skin (Fig. 2) which might be due to presence of moisturizing agent in their formulations. These results indicated that P-I and P-IV could be more suitable for people with dry skin as they can hydrate their skin better than P-II and P-III. 


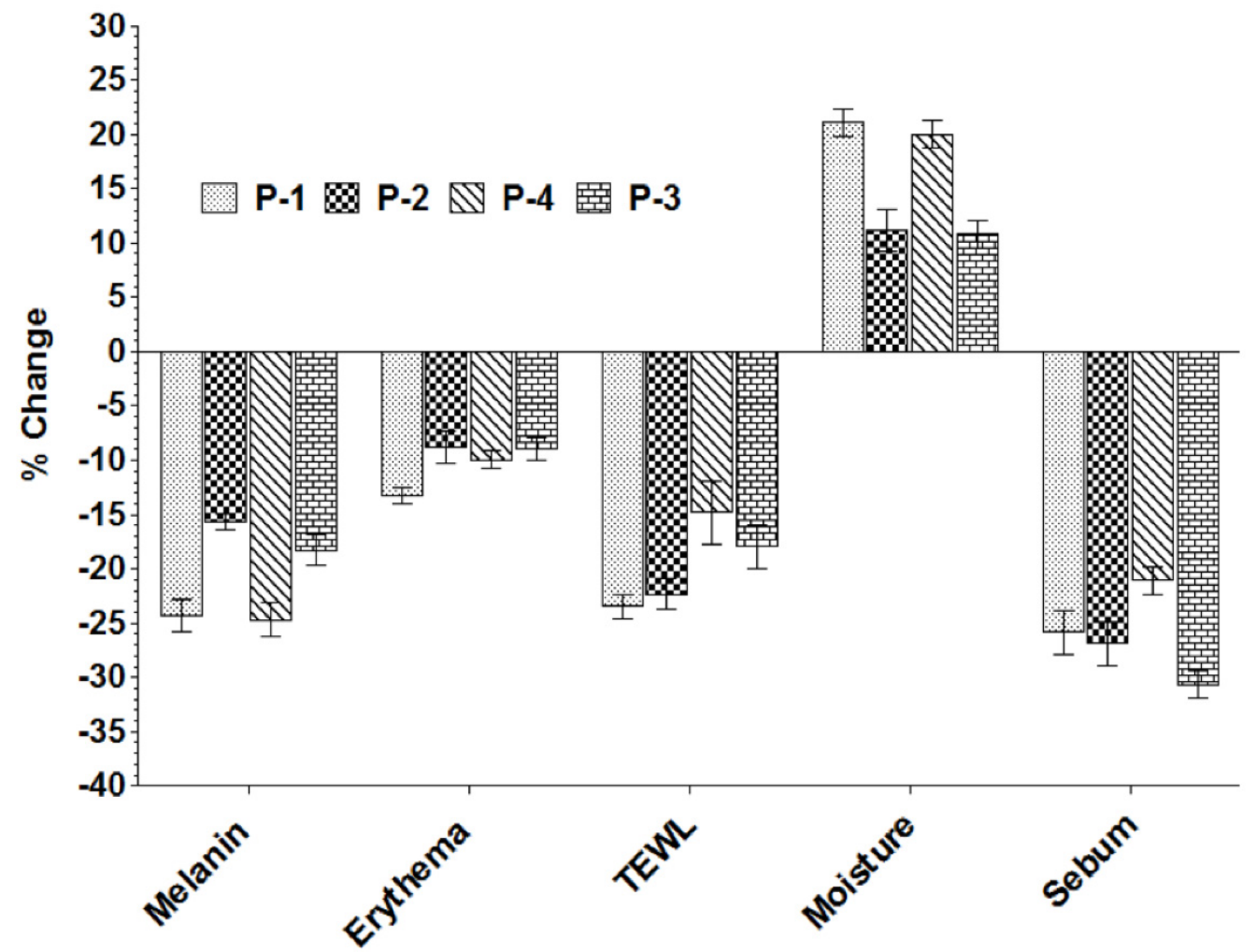

Fig. (2). The net percent change in skin melanin, erythema, TEWL, sebum, and moisture at the end of 8 week study. Mean \pm SEM ( $n=9)$.

Table 4. Results of Patch Test with Volunteer Where Average Points Represents the Point Scored by creamsP-I, P-II, P-III and P-IV on Point Scale of 5

\begin{tabular}{|l|c|c|c|c|}
\hline \multicolumn{1}{|c|}{ Parameter } & Average Points P-I & Average Points P-II & Average Points for P-III & Average Points P-IV \\
\hline \hline Ease of application & 4.45 & 3.93 & 3.8 & 4.25 \\
\hline Spreadability & 4.4 & 3.97 & 3.75 & 4.2 \\
\hline Sense after application & 4.47 & 3.76 & 3.78 & 4.3 \\
\hline Irritation & 4.42 & 3.79 & 3.77 & 4.22 \\
\hline Shine on skin & 4.44 & 3.92 & 3.91 & 4.31 \\
\hline Sense of softness & 4.5 & 3.86 & 3.88 & 4.24 \\
\hline
\end{tabular}

\subsubsection{Panel Test}

Panel test was conducted with the volunteers at the end of study to get their sensory evaluation about the creams. The average points scored by creams on scale of 5 are shown in Table 4. From the test, creams P-I and P-IV scored more than 4.25 points for all the sensory parameters whereas cream P-II and P-III scored less than 4 points.

\section{CONCLUSION}

This study concludes that when In-vitro stability studies of P-1, P-2, P-3 and P-4 in different time intervals i.e. at $0 \mathrm{hr}$ and then after $12 \mathrm{hrs}, 24 \mathrm{hrs}, 48 \mathrm{hrs}, 96 \mathrm{hrs}, 8$ days, 15days, 30 days, 45 days and 60 days kept at different environmental conditions i.e. $8^{\circ} \mathrm{C}, 25^{\circ} \mathrm{C}, 40^{\circ} \mathrm{C}$ and $40^{\circ} \mathrm{C}+75 \% \mathrm{RH}$ for a period of 60 days were done, it was observed that there was no change in colour of P-1, P-2, P-3 and P-4 throughout study period. There was no liquefaction observed in samples of products kept at different conditions except that after 45 days liquefaction was observed in samples of P-2 kept at $40^{\circ}$ $\mathrm{C}$ and $40^{\circ} \mathrm{C}+75 \% \mathrm{RH}$ which remained same till 60 days. There was no phase separation observed in samples of products at all storage conditions except that after 45 days samples of P-2 kept at $40^{\circ} \mathrm{C}$ and $40^{\circ} \mathrm{C}+75 \% \mathrm{RH}$ was separated into two different phases which remained same till 60 days. Electrical conductivity values of samples of products $\mathrm{P}-1, \mathrm{P}-2, \mathrm{P}-3$ and $\mathrm{P}-4$ at all storage conditions remained almost same except that electrical conductivity values of samples of P-2 kept at $40^{\circ} \mathrm{C}$ and $40^{\circ} \mathrm{C}+75 \% \mathrm{RH}$ were significantly increased. The $\mathrm{pH}$ values showed slight variations during 60 days study period.

In-vivo study was performed by doing dermatological tests on human skin and volunteers were selected under the limitation of volunteer protocols and then firstly patch test was performed to check any irritation after application of any of products to be used during study period of 8 weeks according to which only slight increase in skin erythema level was observed after 24 hrs. There was decrease in skin 
melanin content after application of products but significant decrease in melanin content of volunteers was observed after application of P-1 and P-4. P-2 and P-3 also have slight whitening effects but $\mathrm{P}-1$ and $\mathrm{P}-4$ have prominent whitening effects. All of products used by volunteers on cheeks decreased skin erythema content and produced no skin irritation throughout the study period and by comparing effects of products on erythema content it was observed that P-1 decreased erythema content more than other products. Skin TEWL was decreased after application of all products being studied and when effect of products was compared it was observed that only P-4 decreased TEWL in lesser quantity as compared to P-1, P-2 and P-3. Skin sebum content was also reduced on application of products in same pattern.

The moisture content of skin after application of P-1, P-2, P-3 and P-4 was increased throughout the study period but prominent effects were produced by $\mathrm{P}-1$ and $\mathrm{P}-4$.

The panel test was also performed in which different parameters of sensory evaluation (i.e. ease of application, spread ability, sense just after application, sense in long term, irritation, shine on skin and sense of softness) were observed for P-1, P-2, P-3 and P-4 after their application on the cheeks of human volunteer according to which P-1 and P-4 got better points by volunteers than P-2 and P-3.

\section{CONFLICT OF INTEREST}

The authors confirm that this article content has no conflicts of interest.

\section{ACKNOWLEDGEMENTS}

Declared none.

\section{REFRENCES}

[1] Gillbro, J.M.; Olsson, M.J. The melanogenesis and mechanisms of skin-lightening agents - existing and new approaches. Int. J. Cosmetic Sci., 2011, 33, 210-221.
[2] Son, K.H.; Heo, M.Y. The evaluation of depigmenting efficacy in the skin for the development of new whitening agents in Korea. Int. J. Cosmetic Sci., 2012, 34: 1-10.

[3] Schallreuter, K.U.; Kothari, S.; Chavan, B.; Spencer, J.D. Regulation of melanogenesis controversies and new concepts. Exp. Dermatol., 2008, 17, 395-404.

[4] Parvez, S.; Kang, M.; Chung, H.S.; Cho, C.; Hong, M.C.; Shin, M.K.; Bae, H. Survey and mechanism of skin depigmenting and lightening agents. Phytother. Res., 2006, 20, 921-934.

[5] Nordlund, J.J.; Boissy, R.E.; Hearing, V.J.; King, R.A.; Ortone, J.P The Pigmentary System: Physiology and Pathophysiology, New York Oxford University Press, 1998.

[6] Prota, G. The role of peroxidase in melanogenesis evisited. Pigm. Cell Res., 1992, 2, 25-31.

[7] Hearing, V.J., Unraveling the melanocyte. Am. J. Hum. Genet., 1993, 52, 1-7.

[8] Chang, T.S. An updated review of tyrosinase inhibitors. Int. J. Mol. Sci., 2009, 10, 2440-2475.

[9] Briganti, S.; Camera, E.; Picardo, M. Chemical and instrumental approaches to treat hyperpigmentation. Pigm. Cell Res., 2003, 16, 101-110.

[10] Dadzie, O.E.; Petit, A. Skin bleaching: highlighting the misuse of cutaneous depigmenting agents. J. Eur. Acad. Dermatol., 2009, 23, 741-750.

[11] Lambers, H.; Piessens, S.; Bloem, A.; Pronk, H.; Finkel, P. Natural skin surface $\mathrm{pH}$ is on average below 5 , which is beneficial for its resident flora. Int. J. Cosmetic Sci., 2006, 28, 359-370.

[12] Agar, N.; Young, A.R. Melanogenesis: a photoprotective response to DNA damage? Mutat. Res-Fund. Mol. M., 2005, 571, 121-132.

[13] Espinal-Perez, L.E.; Moncada, B.; Castanedo-Cazares, J.P. A double-blind randomized trial of $5 \%$ ascorbic acid vs. $4 \%$ hydroquinone in melasma. Int. J. Dermatol., 2004, 43, 604-607.

[14] Haddad, A.L.; Matos, L.F.; Brunstein, F.; Ferreira, L.M.; Silva, A.; Costa, D. Jr. A clinical, prospective, randomized, doubleblind trial comparing skin whitening complex with hydroquinone $v s$. placebo in the treatment of melasma. Int. J. Dermatol., 2003, 42, 152-156.

[15] Arndt, K.A.; Fitzpatrick, T.B. Topical use of hydroquinone as a depigmenting agent. J. Am. Med. Assoc., 1995, 194, 965-967.

[16] Amer, M.; Metwalli, M. Topical hydroquinone in the treatment of some hyperpigmentary disorders. Int. J. Dermatol., 1998. 37, 449450.

[17] Fujiwara, Y.; Sahashi, Y.; Aritro, M.; Hasegawa, S.; Akimoto, K.; Ninomiya, S.; Sakaguchi, Y.; Seyama, Y. Effect of simultaneous administration of vitamin $\mathrm{C}$, L-cysteine and vitamin $\mathrm{E}$ on the melanogenesis. Biofactors, 2004, 21, 415-418.

[18] Smit, N.; Vicanova, J.; Pavel, S. The hunt for natural skin whitening agents. Int. J. Mol. Sci., 2009, 10, 5326-5349.

Received: May 29, 2013

Revised: August 22, 2013

Accepted: September 11, 2013

(C) Mustafa et al.; Licensee Bentham Open.

This is an open access article licensed under the terms of the Creative Commons Attribution Non-Commercial License (http://creativecommons.org/licenses/by$\mathrm{nc} / 3.0 /$ ), which permits unrestricted, non-commercial use, distribution and reproduction in any medium, provided the work is properly cited. 